\title{
EVALUASI KINERJA JARINGAN IRIGASI WILAYAH KADIPATEN UNTUK MENINGKATKAN EFEKTIVITAS DAN EFISIENSI PENGELOLAAN AIR IRIGASI
}

\author{
Abdul Kholiq ${ }^{1)}$, Maulana Aziz ${ }^{2)}$, Arief Rijaludin ${ }^{3)}$ Lia Lailla Nurjamilah ${ }^{4)}$ \\ Program Studi Teknik Sipil, Fakultas Teknik, Universitas Majalengak ${ }^{1)}$ \\ Email: choliq_fastac@yahoo.co.id/choliqfastac@gmail.com \\ Program Studi Teknik Sipi;, Fakultas Teknik, Universitas Majalengak ${ }^{2)}$ \\ Email: maulanaaziz@gmail.com \\ Program Studi Teknik Sipil, Fakultas Teknik, Universitas Majalengak ${ }^{3)}$ \\ Email: rijaludin@gmail.com \\ Program Studi Teknik Sipil, Fakultas Teknik, Universitas Majalengak ${ }^{4)}$ \\ Email: dziarifqi@gmail.com
}

\begin{abstract}
ABSTRAK
Daerah Irigasi Kamun dibagi menjadi 2 (dua) Saluran Induk yaitu Saluran Induk Cilutung Barat dan Saluran Induk Cilutung Timur dengan luas areal 5.151 ha. Air irigasi dan jaringan irigasi dapat member manfaat yang maksima lsebagaimana direncanakan apabila dikelola secara efektif dan efisien. Salah satu persoalan utama yang terjadi dalam penyediaan air irigasi adalah semakin langkanya ketersediaan air (water scarcity) pada waktu-waktu tertentu. Pada sisi lain permintaan air untuk berbagai kebutuhan cenderung semakin meningkat sebagai akibat peningkatan jumlah penduduk, beragamnya pemanfaatan air, berkembangnya pembangunan, serta kecenderungan menurunnya kualitas air akibat pencemaran oleh berbagai kegiatan. Berdasarkan perhitungan debit aliran saluran rencana disaluran induk Cilutung Barat dari BLK. 1 s/d BLB. 5 diperoleh efisiensi sebesar 96,24 \%. Sementara berdasarkan perhitungan debit saluran aktual diperoleh efisiensi penyaluran air di saluran induk Cilutung Barat dari BLK. 1 s/d BLB. 5 sebesar 92, $46 \%$. Jika dibandingkan dengan kondisi normal efisiensi untuk saluran induk yaitu 90\% maka irigasi ini tergolong efisien penyalurannya. Dari hasil perhitungan Qaktual lebih kecil dibanding Qkebutuhan, yang artinya penampang saluran tidak mendukung untuk mengalirkan air sesuai kebutuhan air di sawah pada saat awal musim tanam. Untuk memenuhi kebutuhan air padi di sawah, sebaiknya penampang saluran diperbesar dan menutup semua bocoran pada saluran.
\end{abstract}

Kata Kunci : Irigasi, Debit Aliran, Debit Rencana, Jaringan

\section{PENDAHULUAN}

\section{Latar Belakang}

Salah satu persoalan utama yang terjadi dalam penyediaan air irigasi adalah semakin langkanya ketersediaan air (water scarcity) pada waktu-waktu tertentu. Pada sisi lain permintaan air untuk berbagai kebutuhan cenderung semakin meningkat sebagai akibat peningkatan jumlah penduduk, beragamnya pemanfaatan air, berkembangnya pembangunan, serta kecenderungan menurunnya kualitas air akibat pencemaran oleh berbagai kegiatan (Bustomi, 2003). Permasalahan lain dalam penyediaan air irigasi adalah dalam hal pengaturan dan pendistribusian atau operasi dan pemeliharaan. Secara teknis pengaturan dan pendistribusian air irigasi dapat direncanakan dan dilakukan secara akurat dan optimum berdasarkan teknologi yang ada. Namun masih terdapat kendala besar dalam pengaturan dan pendistribusian air yang berasal dari faktor non teknis seperti faktor sosial, ekonomi dan budaya dari pemakai dan pengguna air irigasi yang tergabung dalam kelembagaan Perkumpulan Petani Pemakai Air (P3A). Dalam perkembangan selama ini, pengoperasian irigasi di daerah irigasi Kamun diduga telah mengalami banyak perubahan kondisi dan penurunan fungsi. Daerah Irigasi Kamun merupakan Daerah Irigasi teknis yang mengambil air dari Sungai Cilutung melalui bendung tetap 
yaitu bendung Kamun. Dengan sistem irigasi permukaan Daerah Irigasi Kamun direncanakan (didesain) mengairi areal pertanian di tiga kecamatan yang berada di Kabupaten Majalengka yaitu Kecamatan Kadipaten, Kecamatan Kertajati, dan Kecamatan Jatitujuh. (UPTD Jaringan Irigasi Wilayah Kadipaten, 2015). Daerah Irigasi Kamun dibagi menjadi 2 (dua) Saluran Induk (Primer) yaitu Saluran Induk Cilutung Kepala (LK) dan Saluran Induk Cilutung Barat (LB). Sedangkan Saluran Sekunder terdiri dari 4 (Empat) Saluran Sekunder yaitu Saluran Sekunder Jatitujuh (JTH), Saluran Sekunder Kertawinangun (KTG), Saluran Sekunder Gempol (GPL), dan Saluran Sekunder Pasiripis (PI) yang terletak di UPTD Jaringan Irigasi Wilayah Kadipaten dengan luas areal 3.503 ha.

\section{Tujuan dan Manfaat Penelitian}

a. Tujuan Penelitian

Tujuan dari penelitian ini adalah untuk mengetahui kinerja jaringan irigasi saluran induk Cilutung Barat dan juga untuk mengetahui tingkat efesiensi dan efektifitas saluran induk Cilutung Barat.

b. Manfaat Penelitian

$\checkmark$ Dapat mengetahui kinerja jaringan irigasi Cilutung Barat.

Hasil dari penelitian ini diharapkan dapat menjadi referensi dan pengajuan dalam perencanaan kontruksi bagi pemeliharaan jaringan irigasi Saluran Induk Cilutung Barat terhadap UPTD Jaringan Irigasi Wilayah Kadipaten untuk kedepannya.

\section{METODOLOGI}

\section{Tahap Persiapan}

Tahap persiapan merupakan rangkaian kegiatan sebelum memulai pengumpulan data dan pengolahannya. Dalam tahap awal ini disusun halhal penting yang harus dilakukan dengan tujuan supaya kegiatan terstruktur, terkoordinasi dan mendapatkan hasil seperti yang direncanakan. Adapun tahapan tersebut antara lain: a. Studi pustaka mengenai masalah yang berhubungan dengan bendung beserta fasilitasfasilitasnya dan jaringan irigasinya.

b. Menentukan kebutuhan data.

c. Pengadaan persyaratan administrasi.

d. Mendata instansi yang akan dijadikan narasumber.

e. Survey ke lokasi untuk mendapatkan Gambaran umum kondisi di lapangan.

\section{Teknik Pengumpulan Data}

Studi pustaka dilakukan dengan mengumpulkan dan mempelajari buku, jurnal atau literatur lain yang berhubungan dengan judul yang dibahas dan mengumpulkan data-data yang diperlukan untuk referensi.

\section{Data Primer}

Data primer yang digunakan dalam pnelitian ini adalah data pengukuran Inflow - Outflow untuk setiap saluran pegamatan. Hal ini dapat dilakukan dengan mengukur debit inflow pada pangkal saluran dan debit outflow pada ujung saluran dengan menggun akan current meter dan persamaan Manning.

\section{Data Sekunder}

Kegiatan yang akan dilakukan dalam tahap pengambilan data sekunder adalah pengumpulan semua data yang akan digunakan dalam analisis data dari berbagai instansi.

a. Data Studi literatur

Untuk studi literatur ini perlu diperhatikan supaya kegiatan yang akan dilaksanakan berdasarkan teori yang sudah ada dan bagaimana tatacara pemecahan masalah dari kegiatan tersebut. Langkah awal yang harus dilaksanakan adalah mengumpulkan data berupa buku catatan, buku hasil studi terdahulu maupun gambar lain- lain yang dapat digunakan sebagai referensi dalam pelaksanaanya.

b. Data Topografi

Data Topografi, terdiri dari :

$\checkmark$ Peta lokasi / Skema Jaringan Irigasi.

$\checkmark$ Peta dimensi saluran. 
Data topografi digunakan untuk mengetahui kondisi lapangan di sekitar jaringan irigasi wilayah kadipaten Kabupaten Majalengka.

a. Data Hidrologi

Data Hidrologi, terdiri dari :

$\checkmark$ Data curah hujan maksimum dan hujan ratarata.

$\checkmark$ Data debit air.

Data hidrologi menyangkut data curah hujan, catatan debit pada daerah yang mempengaruhi dalam perencanaan. Data ini harus homogen dan independen serta representative. Data yang homogen artinya data berasal dari populasi yang sama, dalam arti lain, stasiun pengumpulan data tidak pernah dipindah dan tidak ada gangguan lainnya yang bisa menyebabkan sifat data yang terkumpul menjadi berbeda. Data yang terkumpul berupa data curah hujan selama minimal 10 tahun. Data ini akan digunakan dalam menganalisis kebutuhan air, tingkat efisiensi dan debit aliran aktual saluran.

b. Data Klimatologi

Data klimatologi terdiri dari :

$\checkmark$ Temperatur bulanan rata-rata $\left({ }^{\circ} \mathrm{C}\right)$

$\checkmark$ Kecepatan angin rata-rata (m/detik)

$\checkmark$ Kelembaban udara relatif rata-rata $(\%)$

$\checkmark$ Lamanya penyinaran matahari rata-rata (\%)

c. Data Lain, berupa :

$\checkmark$ Data kebutuhan air yang selama ini dipakai untuk perencanaan Operasi dan Pembagian air di Daerah Irigasi yang bersangkutan.

$\checkmark$ Catatan tanaman (areal yang ditanami) menurut musim, jenis tanaman (palawija, tebu, dll) intensitas tanam dan hasil untuk lima tahun terakhir (Sumber data terlampir).

$\checkmark$ Data lainnya tentang status sekarang, kendala - kendala dan masalah-masalah dalam Operasi dan Pemeliharaan, sebagaimana dibutuhkan untuk System Planning.

\section{Teknik Analisis dan Pengolahan Data}

\section{a. Analisis Hidrologi}

Pada penelitian ini digunakan data curah hujan selama 10 tahun yang tercatat mulai tahun 2005 sampai dengan tahun 2014 pada stasiun hujan Karangsambung No. 21 yang bertempat di Karangsambung dengan tinggi di atas permukaan laut $48,6 \mathrm{~m}$.

Kriteria Perencanaan irigasi mengusulkan hitungan hujan efektif berdasarkan data pengukuran curah hujan dengan panjang pengamatan 10tahun.Untuk irigasi padi curah hujan efektif $1 / 2$ bulanan diambil $70 \%$ dari curah hujan minimum dengan periode ulang rencana tertentu dengan kemungkinan kegagalan $20 \%$ (Curah hujan $\mathrm{R}_{80}$ ). Analisis hidrologi dalam pelaksanaan pekerjaan ini lebih pada analisa ketersediaan air dan kebutuhan air. Tujuan analisis ini adalah untuk mengetahui karakteristik hujan, debit atau potensi air. Data klimatologi yang digunakan diambil dari kantor BMKG Jatiwangi yang kemudian diolah dengan menggunakan software cropwat 8.0 untuk mendapatkan nilai ETo. Cropwat 8.0adalah program komputer untuk perhitungan kebutuhan air tanaman dan kebutuhan irigasi berdasarkan data tanah, iklim dan tanaman.

\section{Mengukur Debit Aliran}

Debit aliran dihitung menggunakan rumus :

$$
\mathrm{Q}=\mathrm{V} \times \mathrm{A}
$$

\section{Analisis Kebutuhan Air}

Kebutuhan air irigasi adalah jumlah volume air yang diperlukan untuk memenuhi kebutuhan evapotranspirasi, kehilangan air, kebutuhan air untuk tanaman dengan memperhatikan jumlah air yang diberikan oleh alam melalui hujan dan kontribusi air tanah.

\section{Analisis Tingkat Efisiensi dan Efektifitas}

a. Efisiensi Saluran

$$
E c=\frac{\text { debit out flow }}{\text { debit inflow }} \times 100 \%
$$


b. Tingkat efektivitas akan diukur dari Indek Luas Areal (IA), dengan rumusan berikut :

$$
I A=\frac{\text { Luas areal terairi }}{\text { Luas rancangan }} \times 100 \%
$$

Adapun bagan alir atau flow chart Evaluasi Kinerja Jaringan Irigasi Wilayah Kadipaten adalah sebagai berikut:

\section{ANALISIS DAN PERHITUNGAN}

\section{Analisis Tingkat Efisiensi}

Mengacu pada Direktorat Jenderal Pengairan (1986) maka efisiensi irigasi secara keseluruhan diambil $90 \%$ dan tingkat tersier $80 \%$. Angka efisiensi irigasi keseluruhan tersebut dihitung dengan cara mengkonversi efisiensi di masingmasing tingkat yaitu $0,9 \times 0,9 \times 0,8=0,648 \approx 65$ $\%$. Saluran irigasi pada Daerah Irigasi Kamun sudah tidak memadai, dikarenakan factor usia pakai yang sudah lama dan kurang pemeliharaan. Untuk itu maka perlu ditinjau ulang efisiensi saluran pada Daerah Irigasi Kamun. Berdasarkan hasil penelitian didapat data debit pada saluran Induk Cilutung Barat, data diambil sampel dari saluran Induk Cilutung Barat (BLK 1 s/d BLB.5).
Tabel.1 Efisiensi pada Saluran Induk Cilutung Barat dengan persamaan manning berdasarkan perhitungan debit aliran rencana.

\begin{tabular}{|c|c|c|c|c|}
\hline Saluran & $\begin{array}{c}\text { Debit } \\
\text { Inflow } \\
\left(\mathrm{m}^{3} / \mathrm{det}\right)\end{array}$ & $\begin{array}{c}\text { Debit } \\
\text { Outflow } \\
\left(\mathrm{m}^{3} / \mathrm{det}\right)\end{array}$ & $\begin{array}{c}\text { Kehilanganai } \\
\mathrm{r}\left(\mathrm{m}^{3} / \mathrm{det}\right)\end{array}$ & Efisiensi \\
BLK 1 - BLB 1 & 5.41 & 5.36 & 0.05 & $99.08 \%$ \\
\hline BLB 1 - BLB 2 & 5.39 & 5.29 & 0.10 & $98.14 \%$ \\
\hline BLB 2 - BLB 3 & 5.29 & 5.27 & 0.02 & $99.62 \%$ \\
\hline BLB 3 - BLB 4 & 5.27 & 4.37 & 0.90 & $82.92 \%$ \\
\hline BLB 4 - BLB 5 & 4.21 & 4.27 & -0.06 & $101.43 \%$ \\
\hline \multicolumn{5}{|c|}{$96.24 \%$} \\
\hline
\end{tabular}

Dari Tabel.1 diperoleh efisiensi penyaluran air berdasarkan perhitungan debit aliran saluran rencana di saluran Induk Cilutung Barat dari BLK $1 \mathrm{~s} / \mathrm{d}$ BLB 5 sebesar 96,24\%. Jika dibandingkan dengan kondisi normal efisiensi untuk saluran induk yaitu $90 \%$ maka irigasi ini tergolong efisien penyalurannya. Di ruas BLB. 4 - BLB. 5 kehilangan debit air sebesar $-0.06 \quad \mathrm{~m}^{3} / \mathrm{det}$ disebabkan karena luas basahnya besar.

Tabel 2. Efisiensi pada Saluran Induk Cilutung Barat dengan persamaan manning berdasarkan perhitungan debit aliran aktual.

\begin{tabular}{|c|c|c|c|c|}
\hline Saluran & $\begin{array}{c}\text { Debit } \\
\text { Inflow } \\
\left(\mathrm{m}^{3} / \mathrm{s}\right)\end{array}$ & \begin{tabular}{|c|}
$\begin{array}{c}\text { Debit } \\
\text { Outflow } \\
\left(\mathrm{m}^{3} / \mathrm{s}\right)\end{array}$
\end{tabular} & $\begin{array}{c}\text { Kehilangan } \\
\text { air }\left(\mathrm{m}^{3} / \mathrm{s}\right)\end{array}$ & Efisiensi \\
\hline BLK.1- BLB.1 & 4.74 & 4.49 & 0.25 & $94.73 \%$ \\
\hline BLB.1- BLB.2 & 4.49 & 4.26 & 0.23 & $94.88 \%$ \\
\hline BLB.2- BLB.3 & 4.26 & 4.17 & 0.09 & $97.89 \%$ \\
\hline BLB.3- BLB.4 & 4.17 & 3.50 & 0.67 & $83.93 \%$ \\
\hline BLB.4- BLB.5 & 3.50 & 3.18 & 0.32 & $90.86 \%$ \\
\hline & $92.46 \%$ \\
\hline
\end{tabular}

Dari Tabel 2 diperoleh efisiensi penyaluran air di saluran Induk Cilutung Barat dari BLK. 1 s/d BLB. 5 sebesar 92,46\%. Jika dibandingkan dengan kondisi normal efisiensi untuk saluran induk yaitu 90\% maka irigasi ini tergolong efisien penyalurannya. 
Tabel.3 Perbandingan $\mathrm{Q}_{\text {rencana }}$ dengan $\mathrm{Q}_{\text {aktual }}$

\begin{tabular}{|c|c|c|c|c|c|c|c|c|c|c|c|c|}
\hline \multirow{2}{*}{ Ruas Saluran } & \multicolumn{4}{|c|}{ Dimensi Rencana } & \multirow{2}{*}{$\begin{array}{l}\text { Vrenc } \\
(\mathrm{m} / \mathrm{dtk})\end{array}$} & \multirow{2}{*}{\begin{tabular}{|l} 
Qrenc \\
$\left(\mathrm{m}^{3} / \mathrm{dtk}\right)$
\end{tabular}} & \multicolumn{4}{|c|}{ Dimensi Aktual } & \multirow{2}{*}{$\left|\begin{array}{c}\text { Vakt } \\
(\mathrm{m} / \mathrm{dtk}\end{array}\right|$} & \multirow{2}{*}{$\begin{array}{c}\text { Qakt } \\
\left(\mathrm{m}^{3} / \mathrm{dtk}\right.\end{array}$} \\
\hline & $\overline{b(m)}$ & $h(\mathrm{~m})$ & $\mathrm{m}$ & 1 & & & $\overline{b(m)}$ & $\mathrm{h}(\mathrm{m})$ & $\mathrm{m}$ & i & & \\
\hline BLK & 4.99 & 1.65 & 1.00 & 0.00013 & 0.50 & 5.41 & 4.50 & 1.61 & 1.00 & 0.00013 & 0.48 & 4.74 \\
\hline BLB. & 5.00 & 64 & 1.00 & 0.00013 & 0 & 5.39 & 0 & 58 & 1.00 & 3 & 0.48 & 4.49 \\
\hline BLB.2-BLB.3 & 4.90 & 1.64 & 1.00 & 0.00013 & 0.49 & 5.29 & 4.30 & 1.55 & 1.00 & 0.00 & 0.47 & 4.26 \\
\hline BLB.3-BLB.4 & 4.88 & 1.64 & 1.00 & 0.00013 & 0.49 & 5.27 & 4.20 & 1.55 & 1.00 & 0.00013 & 0.47 & 4.17 \\
\hline BLB.4-BLB.5 & 4.88 & 1.62 & 1.00 & 0.00013 & 0.40 & 4.21 & 4.10 & 1.55 & 1.00 & 0.00013 & 0.40 & 3.50 \\
\hline BLB.5-BLB.6 & 5.00 & 1.61 & 1.00 & 0.00015 & 0.40 & 4.27 & 3.50 & 1.40 & 1.00 & 0.00015 & 0.46 & 3.18 \\
\hline
\end{tabular}

Sumber :Hasil perhitungan,

\section{Perbandingan Debit Pengaliran Saluran dengan Debit Kebutuhan}

Tabel. 4 Perbandingan debit pengaliran saluran dengan debit kebutuhan

\begin{tabular}{|c|c|c|c|}
\hline Saluran & $\begin{array}{l}\text { Qrenc } \\
\left(\mathrm{m}^{3} / \mathrm{dt}\right)\end{array}$ & $\begin{array}{c}\text { Qakt } \\
\left(\mathrm{m}^{3} / \mathrm{dtk}\right)\end{array}$ & $\begin{array}{c}\text { Qkeb } \\
\left(\mathrm{m}^{3} / \mathrm{dtk}\right)\end{array}$ \\
\hline BLK.1 - BLB.1 & 5.41 & 4.74 & 4.76 \\
\hline BLB.1 - BLB.2 & 5.39 & 4.49 & 4.73 \\
\hline BLB. 2 - BLB. 3 & 5.29 & 4.26 & 4.69 \\
\hline BLB.3 - BLB.4 & 5.27 & 4.17 & 4.65 \\
\hline BLB.4 - BLB.5 & 4.21 & 3.50 & 4.59 \\
\hline
\end{tabular}

Debit kebutuhan didapat dari hasil perhitungan luas areal layanan dikalikan dengan factor kebutuhan air di sawah (Tabel 3). Faktor kebutuhan air diambil yang tertinggi yaitu pada saat awal musim tanam sebesar 1,44 L/det/ha.

Dari Tabel 4 dapat dilihat bahwa Q rencana masih lebih besar dari Q kebutuhan itu berarti seharusnya debit air kebutuhan terpenuhi akan tetapi Q aktual lebih kecil dibandingkan dengan $\mathrm{Q}$ kebutuhan yang artinya $Q$ aktual tidak mencapai debit yang dibutuhkan diakibatkan oleh terjadinya perubahan fisik saluran dan adanya bocoran - bocoran pada saluran.

\section{Analisis Tingkat Efektivitas}

Tingkat efektifitas akan di ukur dari nilai Indek Luas Areal (IA), dengan rumusan berikut :

$$
I A=\frac{\text { Luas areal terairi }}{\text { Luas rancangan }} \times 100 \%
$$

Luas areal terairi dalam analisis efektivitas ini diambil sampel dari data Realisasi luas tanam MT 1 tahun 2013/2014.

Tabel 5. Rincian luas areal terairi pada MT. 1 dari BLK. 1 s/d BLB. 5

\begin{tabular}{|c|c|c|}
\hline No & Saluran & Luas (Ha) \\
\hline 1 & Lb $1 \mathrm{Kr}$ & 17 \\
\hline 2 & Lb $2 \mathrm{Kr}$ & 26 \\
\hline 3 & Lb $3 \mathrm{Kr}$ & 32 \\
\hline 4 & Lb $4 \mathrm{Kr}$ & 38 \\
\hline 5 & Lb $5 \mathrm{Kr}$ & 23 \\
\hline & Jumlah & $\mathbf{1 3 6}$ \\
\hline
\end{tabular}

Tabel. 6 Rincian luas areal terairi pada MT. 2 dari BLK. 1 s/d BLB. 5

\begin{tabular}{|c|c|c|}
\hline No & Saluran & Luas (Ha) \\
\hline 1 & Lb $1 \mathrm{Kr}$ & 17 \\
\hline 2 & Lb $2 \mathrm{Kr}$ & 26 \\
\hline 3 & Lb 3 Kr & 31 \\
\hline 4 & Lb 4 Kr & 37 \\
\hline 5 & Lb 5 Kr & 23 \\
\hline & Jumlah & $\mathbf{1 3 4}$ \\
\hline
\end{tabular}

Tabel.7 Rincian luas areal terairi pada MT. 3 dari BLK. 1 s/d BLB. 5

\begin{tabular}{|c|c|c|}
\hline No & Saluran & Luas (Ha) \\
\hline 1 & Lb $1 \mathrm{Kr}$ & 0 \\
\hline 2 & Lb $2 \mathrm{Kr}$ & 4 \\
\hline 3 & Lb $3 \mathrm{Kr}$ & 4 \\
\hline 4 & Lb $4 \mathrm{Kr}$ & 3 \\
\hline 5 & Lb $5 \mathrm{Kr}$ & 0 \\
\hline & Jumlah & $\mathbf{1 1}$ \\
\hline
\end{tabular}

Luas rancangan dari BLK. 1 sampai dengan BLB. 5

Computer Science | Industrial Engineering | Mechanic Engineering | Civil Engineering 
Tabel. 8 Rincian luas rancangan dari BLK. $1 \mathrm{~s} / \mathrm{d}$ BLB. 5

\begin{tabular}{|c|c|c|}
\hline No & Saluran & Luas (Ha) \\
\hline 1 & Lb $1 \mathrm{Kr}$ & 17 \\
\hline 2 & Lb $2 \mathrm{Kr}$ & 27 \\
\hline 3 & Lb $3 \mathrm{Kr}$ & 32 \\
\hline 4 & Lb $4 \mathrm{Kr}$ & 38 \\
\hline 5 & Lb 5 Kr & 24 \\
\hline & Jumlah & $\mathbf{1 3 8}$ \\
\hline
\end{tabular}

Di lapangan diidentifikasi rasio atau perbandingan luas areal terairi terhadap rancangan luas areal untuk MT. 1 (Periode Oktober - Januari) mencapai 98,55\% dan untuk MT. 2 (Periode Februari - Mei) mencapai 97,10\% sedangkan di MT. 3 (Periode Juni - September) hanya mencapai $7,97 \%$ saja. Jika dilihat dari keseluruhan pada MT. 2 (Periode Februari - Mei) terjadi penrunan indeks sebesar $1.45 \%$ kemudian di MT. 3 (Periode Juni September) terjadi penurunan indeks yang sangat drastis sebesar $89.13 \%$ hal ini menunjukan bahwa pengelolaan air irigasi kurang baik.

Dari perolehan hasil perhitungan dan analisis Kinerja Jaringan Irigasi Wilayah Kadipaten dari BLK. 1 sampai dengan BLB. 5 kurang baik dilihat dari tingkat efesiensi saluran dengan persamaan manning berdasarkan perhitungan debit aliran aktual diperoleh 92, $46 \%$ maka irigasi ini tergolong efesien penyalurannya. Jika dibandingkan dengan kondisi normal efisiensi untuk saluran induk yaitu $90 \%$. Namun dari segi efektivitas pemberian air pada saluran induk dari seluruh target areal yang akan diairi semuanya tidak terairi karena terjadi penrunan indeks sebesar $1.45 \%$ di MT. 2 (Periode Februari - Mei) kemudian di MT. 3 (Periode Juni - September) terjadi penurunan indeks yang sangat drastis sebesar $89.13 \%$ hal ini menunjukan bahwa pengelolaan air irigasi belum optimal.

\section{KESIMPULAN}

Kinerja jaringan irigasi Cilutung Barat dari BLK. 1 sampai dengan BLB. 5 kurang baik, hal ini disebabkan air yang mengalir tidak tepat terhadap areal yang dituju. Hal ini dapat dilihat pada Tabel 5.4. Dari Tabel 5.2 Efisiensi pada Saluran Induk
Cilutung Barat dengan persamaan manning berdasarkan perhitungan debit aliran aktual diperoleh efisiensi penyaluran air dari BLK. $1 \mathrm{~s} / \mathrm{d}$ BLB. 5 sebesar 92,46 \%. Jika dibandingkan dengan kondisi normal efisiensi untuk saluran induk yaitu $90 \%$ maka irigasi ini tergolong efisien penyalurannya.

Dari hasil perhitungan tingkat efektivitas pemberian air pada saluran induk dari seluruh target areal yang akan diairi semuanya tidak terairi karena terjadi penrunan indeks sebesar $1.45 \%$ di MT. 2 (Periode Februari - Mei) kemudian di MT. 3 (Periode Juni - September) terjadi penurunan indeks yang sangat drastis sebesar $89.13 \%$ ini menunjukan pengelolaan air irigasi belum optimal. Penyebab kehilangan air pada saluran induk ini terjadi di saluran sekunder dan saluran tersier.

\section{REFERENSI}

Balai Diklat PU Wilayah II Bandung, 2013. Modul - 3 Pembagian Air Irigasi dan Operasi Bangunan Khusus

Bustomi, F., 2003. Pandangan Petani Daerah Irigasi Glapan Timur Mengenai Hak Atas Air Irigasi. Jurnal Ilmiah VISI, PSI-SDALP Universitas Andalas, Padang.

Diktorat Jendral Pengairan, 1986. Standar Perencanaan Irigasi Kriteria Perencanaan Bagian Jaringan Irigasi (KP-01). Departemen Pekerjaan Umum, CV. Galang Persada, Bandung.

Diktorat Jendral Pengairan, 1986. Standar Perencanaan Irigasi Kriteria Perencanaan Bangunan Utama (KP-02). Departemen Pekerjaan Umum, CV. Galang Persada, Bandung.

Hendayana, Rachmat. Kajian Efisiensi dan Efektivitas Operasional Jaringan Irigasi Mendukung Produktivitas Usaha Tani Padi Sawah. Balai Besar Pengkajian dan Pengembangan Teknologi Pertanian, Bogor.

Indra, Herryza. 2011. Operasi dan Pemeliharaan Jaringan Irigasi di Daerah Irigasi Jeuram Kabupaten Nagan Raya, Fakultas Pertanian, Teknik Pertanian, UNSYIAH. Banda Aceh. 
Jurnal J-Ensitec: Vol 04|No. 02, Mei 2018

Kuntara MP, Widi. 2011. Evaluasi Efisiensi dan Efektifitas Jaringan Irigasi Dalam Rangka Peningkatan Produksi Pertanian di Namu Sira-sira. Fakultas Teknik, Departemen Teknik Sipil, USU. Medan.
Pasandaran, Efendi, (Editor). 1991. Irigasi di Indonesia Strategi dan Pengembangan. LP3ES, Jakarta.

Undang - Undang Republik Indonesia Nomor 11 Tahun 1974, Tentang Pengairan

UPTD Jaringan Irigasi Wilayah Kadipaten Dinas PSDAPE Kabupaten Majalengka 